\title{
PSIKOEDUKASI CAREGIVER TERHADAP PENINGKATAN PERAWATAN PASIEN DIABETES MELLITUS TIPE II
}

\section{Caregiver Psychoeducation on Diabetes Mellitus Type 2 Care Improvement}

\author{
Andika Siswoaribowo', Mateus Sakundarno², Muhammad Muin ${ }^{3}$ \\ ${ }^{1}$ Program Studi S1 Keperawatan STIKES Karya Husada Kediri \\ ${ }^{2}$ Pasca Sarjana, Universitas Diponegoro, Semarang \\ ${ }^{3}$ Departemen Keperawatan, Fakultas Kedokteran, Universitas Diponegoro, Semarang \\ Korespondensi : siswoari@gmail.com
}

\begin{abstract}
ABSTRAK
Salah satu penyakit kronik yang memerlukan perawatan dalam waktu cukup lama adalah Diabetes Mellitus. Caregiver sebagai orang terdekat dengan penderita dituntut memiliki kemampuan yang mumpuni dalam manajemen Diabetes Mellitus. Tujuan penelitian untuk menganalisis psikoedukasi caregiver terhadap peningkatan perawatan penderita Diabetes Mellitus. Desain penelitian dengan pendekatan quasi experiment prepost with control group. Jumlah responden sebanyak 46 caregiver dan penderita Diabetes Mellitus yang sesuai dengan kriteria inklusi dan eksklusi serta terbagi menjadi 2 kelompok. Persepsi penderita Diabetes Mellitus merupakan variabel dalam penelitian ini. Uji statistik yang digunakan dengan uji $t$ dengan tingkat signifikan $\mathrm{p} 0.05$. Hasil penelitian menunjukkan nilai $\mathrm{p} 0.001<0.05$ maka dapat disimpulkan ada perbedaan persepsi perawatan yang diterima oleh penderita Diabetes Mellitus antara kelompok dan intervensi setelah diberi psikoedukasi pada caregiver. Psikoedukasi caregiver merupakan salah satu upaya untuk meningkatkan manajemen pengelolaan pada penderita Diabetes Mellitus.
\end{abstract}

Kata kunci : Perawatan Pasien Diabetes Mellitus, Psikoedukasi Caregiver

\begin{abstract}
One of the chronic diseases that require treatment in a long time is Diabetes Mellitus. Caregiver as the person closest to the patient is required to have a capable ability in the management of Diabetes Mellitus. The purpose of the study to analyze caregiver psychoeducation of increased care of people with Diabetes Mellitus. Research design with pre experiment approach pre post with control group with the number of respondents as much as 46 caregiver and Diabetes Mellitus patient in accordance with inclusion and exclusion criteria and divided into 2 groups. Perception of Diabetes Mellitus is a variable in this study. Statistical test used with test $t$ test with $p$ value of 0.05 . The results showed that $p$ value $0.001<0.05$ it can be concluded that there is a difference perception of treatment received by people with Diabetes Mellitus between groups and intervention after being given psychoeducation in caregiver. Psychoeducation of caregiver is one of the efforts to improve management in people with Diabetes Mellitus.
\end{abstract}

Keywords : Treatment of Diabetes Mellitus Patients, Psychoeducation of Caregiver 


\section{Pendahuluan}

Kenyamanan baik secara fisik maupun psikologis merupakan salah bentuk dukungan keluarga yang diberikan oleh anggota keluarga (Taylor, 2006). Dukungan caregiver selaku orang terdekat merupakan faktor penting dalam manajemen Diabetes Mellitus. Hal tersebut diperkuat oleh Hensarling (2009) yang menyatakan bahwa dukungan caregiver keluarga merupakan indikator yang dapat memberikan dampak positif terhadap perawatan pada penderita Diabetes Mellitus.

Penyakit metabolik yang ditandai dengan defisiensi insulin dan gangguan fungsi insulin merupakan penyakit Diabetes Mellitus (Tjokroprawiro, 2003; Bare, 2002).

American Diabetes Assosiation mengklasifikasikan Diabetes Mellitus menjadi tiga jenis, yaitu Diabetes tipe 1 (Insulin Dependent Diabetes Mellitus), Diabetes tipe 2 (Non-insulin Dependent Diabetes Mellitus), dan Diabetes Gestasional (WHO, 2012; Tjokroprawiro, 2003).

Prevalensi penderita semakin meningkat, data $I D F$ tahun 2014 mengungkapkan total penderita Diabetes Mellitus sebanyak 387 juta jiwa (8,3\%). Prevalensi Diabetes Mellitus di Indonesia meningkat dari 1,1\% pada tahun 2007 menjadi $2,1 \%$ pada tahun 2013 (Riskesdas, 2013).

Perubahan pola hidup, pertumbuhan ekonomi, menurunnya minat olahraga, pola manajemen penderita yang kurang baik, dan ketidakefektifan dukungan caregiver merupakan sekian banyak faktor penyebab tingginya angka penderita Diabetes Mellitus (WHO, 2012; Trisnawati \& Setyorogo, 2013; Tjokroprawiro, 2003; Sujaya, 2009; Simatupang, 2009; PERKENI, 2011; Hutagaol, 2015).

Manajemen pengelolaan yang baik merupakan kunci untuk menjaga kestabilan gula darah pada penderita Diabetes Mellitus. Caregiver merupakan orang terdekat dengan penderita yang berfungsi untuk menjaga, merawat, dan memenuhi kebutuhan sehari hari, sehingga peran caregiver menjadi faktor penting dalam perawatan (Goldberg \& Salloway Rickler, 2011). Tugas pemberi asuhan, koordinator, dan motivator merupakan peran caregiver dalam perawatan penderita Diabetes Mellitus (Allender et al, 2013).

Caregiver penderita Diabetes memiliki tugas dan tanggung jawab sehingga memiliki kompensasi meluangkan waktu lebih banyak memberikan perawatan pada penderita Diabetes. Sinclair et al (2015) mengatakan kegiatan rutin yang diberikan oleh caregiver diantaranya minum obat $(30 \%)$, pemeriksaan darah (22\%), menyuntikkan insulin (11\%), pekerjaan rumah tangga (82\%), memasak atau menyiapkan makanan (66\%), dan masalah transportasi (56\%). Kegiatan ini berlangsung selama seumur hidup jika dihubungkan dengan penyakit Diabetes (Cherny et al, 2015).

Psikoedukasi adalah salah satu pemberian edukasi yang memiliki program yang bertujuan untuk mengurangi konflik dan mengubah pola komunikasi dalam keluarga untuk menyelesaikan masalah (Townsend, 2012).

Beberapa penelitian sebelumnya mengungkap psikoedukasi efektif dalam memberikan dampak positif dalam keluarga. Selain itu, intervensi yang berfokus kepada keluarga dapat meningkatkan dinamika keluarga dan dapat menurukan konflik keluarga (McBroom \& Enriquez, 2009). Intervensi pada keluarga (caregiver) dibutuhkan untuk mengubah perilaku misalnya kepatuhan diet, kontrol glukosa, dan peningkatan pengetahuan terkait diabetes (Mayberry \& Osborn, 2012; Armour et al, 2005).

Hasil studi pendahuluan pada bulan September 2016 didapatkan angka kejadian Diabetes Mellitus di Kabupaten Kediri pada tahun 2014 sebanyak 2.855 kasus. Selanjutnya pada tahun 2015 meningkat 
menjadi 3.375 kasus, sedangkan pada tahun 2016 sampai dengan bulan Juni sebesar 883 kasus DM (Profil Kesehatan Kab. Kediri).

Studi wawancara di bulan September 2016 pada 10 keluarga dengan DM tipe 2 didapatkan sebanyak 5 keluarga mengatakan tidak mengerti tentang perawatan diabetes yang benar, 3 keluarga mengatakan jarang memperhatikan penderita karena sibuk bekerja misalnya menyiapkan makanan, dan 2 keluarga mengatakan sudah jenuh dan bosan merawat penderita dalam jangka waktu yang lama.

Kemampuan caregiver salah satu indikator utama dalam memberikan dampak terhadap peningkatan perawatan penderita Diabetes Mellitus. Peran keluarga sudah banyak diteliti, akan tetapi penelitian pemahaman tentang kondisi psikologis belum ada.

Caregiver sebagai orang yang selalu ada dibutuhkan oleh penderita seringkali mengabaikan kebutuhan sendiri, tidak pernah memperoleh intervensi, tidak memperoleh pengakuan, kurangnya dukungan dari lingkungan, dan jarang memperoleh penggantian biaya dari banyaknya anggaran pengobatan (Goldberg \& Salloway Rickler, 2011)

\section{Tujuan}

Tujuan penelitian menganalisis psikoedukasi caregiver terhadap peningkatan perawatan pada penderita Diabetes Mellitus Tipe II.

\section{Metode}

Quasi experiment design prepost test with control group merupakan jenis dan desain pada penelitian ini (Nursalam, 2011). Intervensi psikoedukasi diberikan pada caregiver kelompok eksperimen, sedangkan pendidikan kesehatan diberikan pada kelompok kontrol. Penelitian dilakukan di wilayah kerja Puskesmas Bendo antara tanggal 13 Juni hingga 15 Juli 2017.

Caregiver dan penderita Diabetes Mellitus merupakan populasi yang berjumlah 46. Untuk caregiver dengan kriteria inklusi diantaranya jenis kelamin perempuan, tingkat pendidikan (SD, SMP dan SMA), bersedia mengikuti semua sesi dalam psikoedukasi, caregiver tinggal bersama penderita dan usia 34-50 tahun.

\section{Hasil}

Tabel 1. Distribusi Frekuensi

Responden Menurut Pendidikan, Pekerjaan, Keterpaparan Informasi dan Tingkat Pendapatan Caregiver $(\mathrm{n}==46)$

\begin{tabular}{|c|c|c|c|c|}
\hline \multirow[t]{2}{*}{ Variabel } & \multicolumn{2}{|c|}{$\begin{array}{c}\text { Eksperimen } \\
(\mathrm{n}=\mathbf{2 3})\end{array}$} & \multicolumn{2}{|c|}{$\begin{array}{l}\text { Kontrol } \\
(\mathbf{n}=\mathbf{2 3})\end{array}$} \\
\hline & $\mathbf{F}$ & $\%$ & f & $\%$ \\
\hline \multicolumn{5}{|l|}{ Tingkat Pendidikan } \\
\hline a. $\mathrm{SD}$ & 4 & 17.4 & 6 & 26.1 \\
\hline b. SMP & 5 & 21.7 & 5 & 21.7 \\
\hline c. SMA & 15 & 65.2 & 12 & 52.2 \\
\hline \multicolumn{5}{|c|}{ Penghasilan Caregiver } \\
\hline a. $\geq \underset{1.540 .000 .61}{R p}$ & 11 & 47.8 & 10 & 43.5 \\
\hline $\begin{array}{cc}\text { b. }<\text { Rp. } \\
1.540 .000 .61\end{array}$ & 12 & 52.2 & 13 & 56.5 \\
\hline \multicolumn{5}{|l|}{ Pekerjaan Caregiver } \\
\hline a. Swasta & 3 & 13.0 & 4 & 17.4 \\
\hline b. Wiraswasta & 5 & 21.7 & 7 & 30.4 \\
\hline c. Petani & 2 & 8.70 & 5 & 21.7 \\
\hline d. IRT & 13 & 56.5 & 11 & 47.8 \\
\hline \multicolumn{5}{|c|}{ Keterpaparan Informasi DM } \\
\hline a. $\mathrm{Ya}$ & 21 & 91.30 & 19 & 82.6 \\
\hline b. Tidak & 2 & 8.30 & 4 & 17.4 \\
\hline
\end{tabular}

Tingkat pendidikan pada kelompok kontrol adalah SMA sebesar 52,17\%, sedangkan kelompok eksperimen tingkat pendidikan SMA sebesar 65,22 \%. Sebagian besar responden caregiver baik di kelompok eksperimen sebesar 52,17. Lebih dari setengah $(56,52 \%)$ pekerjaan caregiver pada kelompok eksperimen dan kontrol sebagai ibu rumah tangga sebesar $47,82 \%$ dan hampir seluruhnya pada kelompok eksperimen $(91,30 \%)$ serta kelompok kontrol $(82,60 \%)$ caregiver sudah terpapar infomasi tentang Diabetes Mellitus. 
Tabel 2. Persepsi Penderita dalam Menerima Perawatan Caregiver Sebelum dan Setelah Dilakukan Intervensi pada Kelompok Kontrol

\begin{tabular}{clrr}
\hline Variabel & Kelompok & Mean & \multicolumn{1}{c}{ Std } \\
\hline Persepsi & Pre Test & 65.2 & 5.520 \\
\cline { 2 - 4 } Penderita DM & Post Test & 69.7 & 5.536 \\
\hline
\end{tabular}

Rerata persepsi penderita sebelum dilakukan intervensi sebesar 65,2, sedangkan setelah intervensi pendidikan kesehatan meningkat menjadi 69,7 .

Tabel 3. Persepsi Penderita dalam Menerima Perawatan Caregiver Sebelum dan Setelah Dilakukan Intervensi pada Kelompok Eksperimen

\begin{tabular}{cccc}
\hline Variabel & Kelompok & Mean & Std \\
\hline $\begin{array}{c}\text { Persepsi } \\
\text { Penderita } \\
\text { DM }\end{array}$ & Pre Test & 69.4 & 6.991 \\
\cline { 2 - 4 } & Post Test & 82.8 & 4.488 \\
\hline
\end{tabular}

Rerata persepsi penderita sebelum dilakukan intervensi sebesar 69,4, sedangkan setelah intervensi psikoedukasi meningkat menjadi 82,8 .

Hasil uji Independent $T$ didapatkan signifikansi ( $p$-value) sebesar $0,001 \leq 0,05$ yang berarti menunjukkan bahwa psikoedukasi caregiver dapat meningkatkan perawatan penderita pada Diabetes Mellitus.

\section{Pembahasan}

Salah satu kunci pengelolaan manajemen Diabetes Mellitus adalah kemampuan caregiver. Psikoedukasi merupakan bagian intervensi keperawatan yang mampu meningkatkan hal tersebut.

Pemberian informasi serta edukasi melalui pola komunikasi terapeutik dalam perawatan keluarga adalah salah satu faktor dalam psikoedukasi (Townsend 2012; Friedman 2010).

Melalui psikoedukasi caregiver dapat meningkatkan pengetahuan (kognitif) melalui pemberian informasi dan edukasi serta rehabilitasi suatu penyakit sehingga mampu meningkatkan dukungan perawatan.

Tujuan utama psikoedukasi saling bertukar informasi perawatan, komplikasi serta membantu caregiver mengerti tentang penyakit penderita diantaranya tanda gejala hingga penatalaksanaan, sehingga caregiver diharapkan dapat memberikan perawatan secara maksimal.

Pernyataan diatas diperkuat oleh teori yang menyatakan psikoedukasi mempunyai peran dan fungsi mengembangkan pola hubungan komunikasi melalui saling memahami perasaan, masalah yang muncul akibat merawat anggota keluarga yang sakit, mengatasi beban pada keluarga, serta menggunakan fasilitas kesehatan (Townsend, 2012). Tujuan utama yang lain adalah membawa dampak positif dalam keluarga sehingga tercipta hubungan antar anggota keluarga (Shives, 2008)

Pada penelitian ini, psikoedukasi dilakukan dalam 5 sesi, dimana setiap sesi dilakukan dalam waktu 30-45 menit dengan jumlah caregiver setiap kelompok 5 orang.

Pada sesi pertama dan kedua psikoedukasi, caregiver akan menceritakan pengalamannya selama memberikan perawatan sehingga caregiver akan saling bertukar informasi dengan caregiver yang lain. Pada sesi ini akan dijelaskan manfaat serta tujuan yang akan diperoleh diantaranya tentang pengertian hingga penatalaksanaan Diabetes Mellitus. Dengan begitu diharapkan caregiver akan mendapatkan informasi sehingga mampu menambah pengetahuan dan wawasan.

Sesi ketiga, terapis dalam hal ini peneliti memberikan informasi dalam manajemen stres yang dihadapi oleh caregiver selama perawatan. Dengan pemberian metode tersebut caregiver diharapkan 
tidak merasa jenuh dan bosan, sehingga akan lebih optimal dalam memberikan pelayanan perawatan.

Sesi keempat, pada sesi ini peneliti mengajarkan kepada caregiver tentang pengelolaan manajemen beban akibat perawatan jangka waktu yang lama. Sesi kelima, peneliti dengan caregiver mendiskusikan sumber-sumber yang dapat menghambat perawatan misalnya keterjangkauan sarana kesehatan, finansial, dan petugas kesehatan.

Pernyataan diatas didukung oleh penelitian Desi Ariyana yang menyebutkan bahwa psikoedukasi mempunyai pengaruh terhadap dukungan psikosoial keluarga pada anggota keluarga dengan penyakit kusta (Rahayu, 2011).

Begitu pula dengan penelitian yang dilakukan oleh Kamalah (2016) menyatakan bahwa psikoedukasi yang diberikan pada caregiver dengan ulkus Diabetes Mellitus efektif dalam menurunkan kecemasan.

\section{Kesimpulan}

Psikoedukasi yang diberikan pada caregiver mampu meningkatkan perawatan pada penderita Diabetes Mellitus.

\section{Daftar Pustaka}

Allender, J. et al., 2013. Community \& Public Health Nursing: Promoting the Public's Health, Wolters Kluwer Health.

Armour, T.A. et al., 2005. The effectiveness of family interventions in people with Diabetes Mellitus: a systematic review. Diabetic medicine: a journal of the British Diabetic Association, 22(10), pp.1295-1305.

Brunner \& Suddarth's, 2002. Textbook of Medical Surgical Nursing, Philadelphia: Linppincott William \& Wilkins.

Brunner \& Suddarth's, 2010. Textbook of Medical Surgical Nursing, Philadelphia: Lippincott William\& Wilkins.
Cherny, N.I. et al., 2015. Oxford Textbook of Palliative Medicine, Oxford University Press.

Friedman, 2010. Buku Ajar Keperawatan Keluarga, Riset, Teori dan Praktik 5th ed., Jakarta: EGC.

Goldberg, A. \& Salloway Rickler, K., 2011. The role of family caregivers for people with chronic illness. Medicine and Health-Rhode Island, 94(2), p.41.

Hensarling, J., 2009. Development and psychometric testing of Hensarling's diabetes family support scale. Degree of Doctor of Philosophy in the graduate School of the Texas's Women's University.

Hutagaol, H., 2015. Pengaruh Gaya Hidup terhadap Kejadian DM Tipe 2 di RSUD Kota Padangsidimpuan Tahun 2014.

Kamalah, Dzil, A., Efektivitas psikoedukasi keluarga pada caregiver pasien ulkus diabetes melitus dalam menurunkan tingkat ansietas ., 2016(2), pp.85-98.

Mayberry, L.S. \& Osborn, C.Y., 2012. Family support, medication adherence, and glycemic control among adults with type 2 diabetes. Diabetes Care, 35(6), pp.1239-1245.

McBroom, L.A. \& Enriquez, M., 2009. Review of family-centered interventions to enhance the health outcomes of children with type 1 diabetes. The Diabetes educator, 35(3), pp.428-438.

Nursalam, 2011. Konsep dan Penerapan Metodologi Penelitian Ilmu Keperawatan 2nd ed., Jakarta: Salemba Medika.

WHO., 2012. Definition and diagnosis of diabetes melitus and intermediate hyperglycemia. Internasional diabetes federation 2006.

PERKENI, 2011. Konsensus Pengelolaan dan Pencegahan Diabetes Mellitus Tipe 2 di Indonesia, Jakarta:

Rahayu, D.A., 2011. Pengaruh Psikoedukasi Keluarga Terhadap Dukungan Psikososial Keluarga Pada Anggota Keluarga dengan Penyakit Kusta di Kabupaten Pekalongan.

RISKESDAS, 2013. Riset Kesehatan Dasar. Penelitian, Badan Pengembangan, 
Andika Siswoaribowo: Psikoedukasi Caregiver Terhadap Peningkatan Perawatan Pasien Diabetes Mellitus Tipe II

Shives, L.R., 2008. Basic Concepts of Psychiatric-mental Health Nursing, Wolters Kluwer / Lippincott Williams \& Wilkins.

Simatupang, M.R., 2009. Pengaruh Pola Konsumsi, Aktivitas Fisik dan Keturunan terhadap Kejadian Obesitas pada Siswa Sekolah Dasar Swasta di Kecamatan Medan Baru Kota Medan.

Sinclair, A.J. et al., 2010. Caring for older adults with Diabetes Mellitus: Characteristics of carers and their prime roles and responsibilities. Diabetic Medicine, 27(9), pp.10551059.

Sujaya, I.N., 2009. Pola Konsumsi Makanan Tradisional Bali sebagai Faktor Risiko Diabetes Melitus Tipe 2 di Tabanan. Jurnal skala husada, 6(1), pp.75-81.

Taylor, 2006. Health Psychology, McGrawHill Education (India)

Tjokroprawiro, A., 2003. Diabetes Mellitus: kelasifikasi, diagnosis dan terapi, Gramedia Pustaka Utama.

Townsend, M.C., 2012. Psychiatric Mental Health Nursing: Concepts of Care in Evidence-based Practice, F.A. Davis Company.

Trisnawati, S.K. \& Setyorogo, S., 2013. Faktor Risiko Kejadian Diabetes Melitus Tipe II Di Puskesmas Kecamatan Cengkareng Jakarta Barat Tahun 2012. Jurnal Ilmiah Kesehatan, 5(1), pp.6-11. 